\title{
A reintegração de crianças e adolescentes institucionalizados vítimas de violência doméstica no espaço escolar ${ }^{1}$
}

\author{
Reintegration of institutionalized children and adolescents, victims of domestic \\ violence into school
}

\section{La reintegracción de niños y adolescentes institucionalizados víctimas de la violencia doméstica en el espacio escolar}

\author{
Diene Monique Carlos', Maria das Graças Carvalho Ferriani", Marta Angélica Iossi Silva"I", \\ Kátia Michelli Bertoldi Arone ${ }^{\mathrm{V}}$
}

\section{RESUMO}

No mundo contemporâneo, crianças e adolescentes estão vulneráveis a atos violentos, sendo vitimizados dentro dos próprios lares. Percebendo a dificuldade de inserção escolar desta população, buscamos com este estudo conhecer e descrever a percepção de professores e funcionários de escolas públicas frente a reintegração de crianças e adolescentes vitimizados no espaço escolar. Pesquisa qualitativa, sendo a coleta de dados realizada por meio de entrevista semi-estruturada e a análise dos dados a partir do método de análise de conteúdo. Constatamos dois núcleos temáticos: A auto-estima de crianças e adolescentes vitimizados e institucionalizados; e Olhar diferenciado - necessidades de apoio. No primeiro, a baixa auto-estima foi evidenciada pelos professores e funcionários como fator explicativo para a timidez ou agressividade manifestada pelas crianças e adolescentes no espaço escolar; no segundo, foi destacada a necessidade de se ter pessoas especializadas para oferecer suporte aos envolvidos com a violência doméstica. Devemos caminhar no sentido de auxiliar os funcionários e professores na busca de atividades e estratégias para trabalhar a questão da violência na vida destas crianças e adolescentes. Assim, poderemos subsidiar melhor as ações voltadas para uma assistência integral à criança e ao adolescente vitimizados e inseridos no espaço escolar.

Palavras chave: Violência doméstica; Criança; Adolescente; Saúde escolar; institucionalização.

\section{ABSTRACT}

In the contemporary world, children and adolescents are vulnerable to violent acts and are victimized in their own homes. Perceiving this population's difficulties in been included in the school system, this study aimed to know and describe teachers' and employees' perception regarding the reintegration of victimized children and adolescents into public school. This is a qualitative research, with data collected through semi-structured interviews and data analysis based on the content analysis, thematic modality. We identified two thematic groups: victimized children's and adolescents' self-esteem; and Differentiated View - need of support. In the first group, the low self-esteem was evidenced by teachers and employees as explicative factor for shyness or aggressiveness of children and adolescents at school. In the second one, the need of specialized people to support those involved with domestic violence was highlighted. We must support employees and teachers in the search of strategies and activities to deal with the violence issue in the life of these children and adolescents. This way, we will be able to support actions directed to the integral assistance of children and adolescents victimized and included in the school system.

Key words: Domestic violence; Child; Adolescent; School health; Institutionalization.

\section{RESUMEN}

En el mundo contemporáneo, niños y adolescentes estan vulnerables a actos

\footnotetext{
${ }^{1}$ Pesquisa financiada pela Fundação de Amparo à Pesquisa do Estado de São Paulo - FAPESP

Graduanda em Enfermagem, Escola de Enfermagem de Ribeirão Preto - USP, Ribeirão Preto - SP. - E-mail: diene_enf@yahoo.com.br

" Professora Titular do Departamento de Enfermagem Materno-Infantil e Saúde Pública, Escola de Enfermagem de Ribeirão Preto - USP. Ribeirão Preto/SP - E-mail: caroline@eerp.usp.br

III Professora Doutora do Departamento de Enfermagem Materno-Infantil e Saúde Pública, Escola de Enfermagem de Ribeirão Preto - USP. Ribeirão Preto/SP - E-mail: maiossi@eerp.usp.br

V Enfermeira graduada pela Escola de Enfermagem de Ribeirão Preto - USP. Ribeirão Preto/SP
} 
violentos, siendo victimizados dentro de los propios hogares. Percibiendo la dificultad de inserción escolar de esta población, buscamos con este estudio conocer y describir la percepción de profesores y empleados de escuelas públicas ante la reintegración de niños y adolescentes victimizados en el espacio escolar. Investigación cualitativa, siendo la recopilación de datos realizada a partir de entrevista semiestructurada y el análisis de datos a partir del análisis temático de contenido. Constatamos dos núcleos temáticos: La auto-estima de niños y adolescentes victimizados e institucionalizados; y Mirar diferenciado - necesidades de apoyo. En el primer, la baja auto-estima fue evidenciada por los profesores y empleados como factor

\section{NTRODUÇÃO}

Muitas crianças e adolescentes atualmente tornam-se vulneráveis a atos violentos, ora como vítimas, ora como agressores. Isto não se configura apenas como um dado estatístico, mas sim como um fato que nos é apresentado cotidianamente nas páginas policiais da imprensa escrita, nos semáforos de nossas avenidas, nos pequenos roubos ocorridos nas praças. A transformação na estrutura etária da população brasileira, ocorrida nas últimas três décadas, resultou no aumento significativo de demanda por políticas sociais básicas no atendimento às crianças e adolescentes. Além disto, esta geração está se desenvolvendo num contexto socioeconômico marcado por profundas desigualdades de oportunidades de inserção no mercado de trabalho e de perspectivas quanto ao futuro, sendo considerado o segmento mais vulnerável aos agravos decorrentes da violência e dos acidentes, os quais, por exemplo, representam a primeira causa de morte entre os adolescentes. Em 2002, foram mais de 15 mil adolescentes mortos por violência e acidentes, representando $62,5 \%$ do total de óbitos nessa faixa etária ${ }^{(1)}$.

A violência possui diversas formas de expressões determinadas pela cultura, pelas relações do macro e microssistema e pelos valores pertencentes a um povo. Atinge de forma mais hostil os sujeitos mais indefesos de uma sociedade, como crianças e mulheres, explicativo para la timidez o agresividad manifiesta por niños y adolescentes en el espacio escolar; en el segundo, fue destacada la necesidad de se tener personas especializadas para ofertar apoyo a los involucrados con la violencia doméstica. Debemos caminar en el sentido de ayudar a los empleados y profesores en la búsqueda de actividades y estrategias a fin de trabajar la cuestión de la violencia en la vida de estos niños y adolescentes. Así, podremos apoyar mejor las acciones dirigidas a una atención integral a los niños y adolescentes victimizados e insertados en el espacio escolar.

Palabras clave: Violencia doméstica; Niño; Adolescente; Salud escolar; Institucionalización.

porém sem poupar os demais. Não está presente apenas nas relações interpessoais, mas também em instituições que exercem poder na sociedade, como família e escolas. Dessa forma, podemos dizer que não há um fato denominado violência, mas sim violências como expressões de manifestação da exacerbação de conflitos sociais cujas especificidades necessitam ser conhecidas $^{(2)}$.

A realidade em que vivem os jovens, em especial aqueles expostos a fatores de vulnerabilidade como da violência intrafamiliar e urbana, a pobreza, da exclusão social, a limitação de acesso a bens e serviços, faz com que construam uma noção de violência tendo por base o que realmente acontece no seu cotidiano; de sua consciência de classe e posição na sociedade; das relações na família e na escola; das mensagens que capta da mídia; de suas experiências; de como subjetivamente processam esses estímulos. A violência já não aparece mais como uma manifestação de busca de mudanças, conforme pensavam Marx e Engels, mas como um subproduto da sociedade dita pós-moderna, movida pela financeirização da vida e pelo consumo. Os freqüentemente prejudicados são os pobres, principalmente os jovens, quando a violência torna-se para eles um mercado de trabalho, uma forma de ter dinheiro, bens de consumo e poder, gerando cada vez mais a exclusão social ${ }^{(2,3)}$.

Infelizmente crianças e adolescentes sofrem violência nas escolas, nas ruas, no 
trabalho clandestino e insalubre; porém o agravante reside no fato de que são vitimizadas principalmente nos lares, onde a relação de poder e hierarquia entre adultos, crianças e adolescentes é muito forte. Constata-se que o padrão de organização das famílias patriarcalcapitalista dentro da sociedade, significa a dupla dominação, do capital e do adulto, propiciando o aparecimento da violência doméstica, onde em geral os pais exercem seu poder através da vitimização de seus filhos, aspirando ao poder exercido sobre eles pela própria sociedade capitalista $^{(4)}$.

A violência doméstica contra crianças e adolescentes é considerada uma violência interpessoal e intersubjetiva; um abuso do poder disciplinar e coercitivo dos pais e responsáveis; redução da vítima à condição de objeto de maus-tratos; uma negação dos valores humanos fundamentais; e o mais grave - pode durar por meses ou anos, pois como pertence à esfera do privado, reveste-se de sigilo especialmente nas camadas altas da sociedade ${ }^{(5,6)}$.

Neste sentido, a criança e o adolescente levam marcas desta violência para o resto de suas vidas dado à importância que a família tem para a formação da personalidade e na reprodução das relações sociais, onde esta deva ser vista como uma construção social, um grupo ativo na formação e transformação dos padrões culturais e afetivos, "como instituição primária, incondicionalmente importante na construção de identidades, valores, afetos e cidadania" ${ }^{(5)}$

Hoje, de acordo com a literatura, sabemos que a violência doméstica determina sentimentos como o desamparo, o medo, a culpa, a raiva, que não podendo ser manifestados, transformam-se em comportamentos distorcidos, perpetuando-se por gerações indefinidamente. Isto porque vivemos numa cultura onde bater nos filhos sempre foi e infelizmente continua sendo um direito reconhecido pelos pais para o bem dos filhos $^{(3,4,7)}$.

De acordo com o Estatuto da Criança e do Adolescente - $\mathrm{ECA}^{(8)}$, frente a uma ameaça ou violação dos direitos da criança e do adolescente, por meio de qualquer forma de violência, pode-se adotar como medida de proteção à vítima, o abrigo em uma entidade (Artigo 101, parágrafo VII). Porém sabemos que o abrigamento promove o rompimento de todas as relações e a perda de vínculos com a família, comunidade e demais grupos sociais. Mesmo nos casos em que o abrigo constitui uma medida provisória e excepcional, este tempo de institucionalização pode se estender por muitos anos, principalmente em um país como o Brasil, que conta com um sistema jurídico deficiente, cujos processos levam muito tempo para serem solucionados.

Uma das grandes problemáticas que circundam a esfera da institucionalização de crianças e adolescentes é a reintegração dos mesmos em nosso meio social, sendo que muitas vezes lhes é negado um de seus maiores direitos e a principal oportunidade para se empoderarem - a educação. Sabemos que a maioria das crianças e adolescentes vitimizados pertence a classes sociais mais desfavorecidas, e este fato traz inúmeras conseqüências.

Quando uma criança ou adolescente nesta situação chega à escola, encontra o preconceito e o temor de grande parte dos professores e funcionários em detrimento ao acolhimento e proteção que deveria receber e que são legalmente previstos em lei. Dado que a escola é um local eminentemente coletivo proporciona a crianças e adolescentes a experimentação da formação da sua identidade para além da família. É justamente neste momento que o indivíduo adquire consciência da sociedade da qual participa, percebendo os condicionamentos sociais a que está sujeito, as diferenças sociais existentes, argumentando consigo próprio e com o mundo sobre as alternativas de mudanças.

Tendo como base o exposto, justificamos nossa preocupação com as barreiras que são criadas para a inserção efetiva de crianças e adolescentes vitimizadas nessa instituição. Nesse sentido propomos a realização deste estudo, cujo objetivo foi descrever e discutir sobre as percepções de professores e funcionários de escolas públicas frente à reintegração, no espaço escolar, de crianças e adolescentes institucionalizados no Centro de Atendimento à Criança e ao Adolescente 
Vitimizados (CACAV), do município de Ribeirão Preto-SP.

\section{PERCURSO METODOLÓGI CO}

Para o delineamento de nossa pesquisa, dadas todas as especificidades já citadas, adotamos a abordagem qualitativa, considerando-a como sendo aquela capaz de "trabalhar com o universo de significados, motivos, aspirações, crenças, valores e atitudes, o que corresponde a um espaço mais profundo das relações, dos processos e dos fenômenos que não podem ser reduzidos à operacionalização de variáveis" ${ }^{(9)}$.

Para a coleta dos dados elegemos a entrevista semi-estruturada, definida como "aquela que parte de certos questionamentos básicos, apoiados em teorias e hipóteses que interessam à pesquisa e que, em seguida, oferecem amplo campo de interrogativa, fruto de novas hipóteses que emergem através das respostas dos informantes" ${ }^{(9)}$. A entrevista com os professores e funcionários das escolas públicas que mantêm contato com as crianças e adolescentes institucionalizados no CACAV permitiu explorar certos questionamentos sobre a recepção destas crianças e adolescentes na escola; as diferenças entre estes e os demais alunos da instituição; o comportamento destas crianças e adolescentes institucionalizados e as barreiras que podem existir para que eles freqüentem a escola.

O presente estudo foi realizado em duas instituições públicas de ensino fundamental de Ribeirão Preto, tendo como critério de escolha o maior número de crianças e adolescentes matriculados nas mesmas e que estão institucionalizados no Centro de Atendimento à Criança e ao Adolescente Vitimizados (CACAV). Como forma de garantir o anonimato destas escolas, as chamaremos de A e B. Estas escolas localizam-se próximas a bairros com desenvolvimento sócio-econômico baixo, inclusive com a existência de favelas em sua região.

O CACAV é uma instituição de gestão municipal, ligada à Secretaria da Cidadania e Desenvolvimento Social. Tem como objetivo principal proporcionar o acolhimento às crianças e aos adolescentes vitimizados, procurando desenvolver o atendimento integral as suas necessidades, buscando preservar a sua identidade e história de vida.

Este estudo teve como sujeitos seis professores e três funcionários das escolas $A$ e $B$ que têm ou já tiveram contato com crianças ou adolescentes institucionalizados no CACAV. Com o objetivo de garantir o anonimato dos relatos, identificamos as entrevistas dos professores e funcionários com a letra $E$, representando entrevista, e foram enumeradas de acordo com a seqüência em que foram realizadas. Procedemos também uma observação de campo, a qual ofereceu dados complementares aos depoimentos.

As entrevistas foram aplicadas pela própria pesquisadora nos meses de outubro, novembro e dezembro de 2006. Cada uma destas teve a duração de aproximadamente 30 minutos. $\mathrm{O}$ instrumento foi testado previamente com professores e funcionários.

Este estudo faz parte do Projeto Temático "A Criança e o Adolescente Alvos de Atos Violentos ou Vítimas Potenciais da Violência", processo no. 2003/13966-9, sendo que este foi aprovado pelo Comitê de Ética em Pesquisa da Escola de Enfermagem de Ribeirão Preto da Universidade de São Paulo em 18 de fevereiro de 2005 processo número 0120/2000,

Para o desenvolvimento do trabalho foi solicitada autorização para a Delegacia de Ensino de Ribeirão Preto, sendo que posteriormente apresentamos o estudo aos diretores, professores e demais funcionários das escolas e às autoridades responsáveis pelo CACAV.

De acordo com a Resolução 196 de 1996 do Conselho Nacional de Saúde, os sujeitos foram informados quanto aos objetivos do estudo, e posteriormente foi solicitada a concordância para participar por meio da assinatura do Termo de Consentimento Livre e Esclarecido. Apenas foram usadas neste estudo as entrevistas devidamente autorizadas.

Analisamos os dados coletados a partir do método de análise de conteúdo ${ }^{(10)}$, segundo as etapas: pré-análise; exploração do material; e tratamento dos resultados e interpretação. 


\section{RESULTADOS E DISCUSSÃO}

Após o processo de organização do material coletado nas entrevistas, de leituras exaustivas deste material e embasados na abordagem teórico-metodológica, emergiram dois núcleos temáticos denominados "A autoestima de crianças e adolescentes vitimizados e institucionalizados" e "Olhar diferenciado necessidades de apoio", apresentados e discutidos a seguir.

\section{A auto-estima de crianças e adolescentes vitimizados e institucionalizados}

Este núcleo está intimamente relacionado com a percepção dos atores sociais sobre o comportamento das crianças e adolescentes vitimizados e institucionalizados, sendo evidenciada a baixa auto-estima como um fator explicativo para determinadas atitudes. Quando questionados sobre o comportamento destas crianças e adolescentes, os sujeitos destacaram que existem na verdade dois extremos de atitudes - de um lado existem crianças que demonstram grande carência e necessidade de afeto e do outro existem aqueles que tornam-se revoltados e agressivos.

Eles são, igual estes que eu citei, são super dóceis, se você não soubesse o problema deles você não diria que eles tinham problemas, super educados. Mas os outros (...) do relacionamento com os outros colegas. Xingamentos, é se caiu uma coisa, se esbarrou, já parte assim pra agressão física, sabe. A revolta mesmo é visível no semblante deles. (E3)

(...) e o que eu vi mesmo foi essa parte que ela era mais carente, sente mais necessidade de carinho, da parte afetiva, de atenção. Tá sempre chamando, perguntando. Ás vezes uma coisa que ela sabe pergunta novamente. Agora, assim eu acho que tem casos de crianças que são violentadas também, que reage com agressividade. (...) depende como a criança trabalha essa violência dentro da cabecinha dela. Porque tem essa criança que vai assimilar e vai trazer aquela atitude que ela recebeu dentro da sala de aula, né, vai agredir os amigos, te agredir verbalmente, e tem casos que parece a falta de afetividade mesmo. (E6)
De acordo com estudo para perceber as estratégias de coping de crianças e adolescentes em situações estressantes ${ }^{(1)}$, a aceitação e a expressão emocional (manifestação do estado emocional) mostraram-se freqüentes nas respostas de crianças. A estratégia de aceitação mostrou-se freqüente principalmente nas situações estressantes envolvendo adultos. Sabe-se, através da literatura, que as práticas educacionais de populações que apresentam baixas condições sócio-econômicas caracterizam-se por um predomínio do autoritarismo e pela exigência de obediência. Este aspecto pode explicar a maior utilização da estratégia de aceitação, já que muitas vezes, diante de adultos, a criança ou o adolescente não encontra alternativa que não seja aceitar a situação e submeter-se a ela.

A estratégia de ação agressiva, ainda segundo este estudo, foi mais freqüente entre os adolescentes, indo ao encontro de uma fala que apresenta as crianças de menor idade como mais carentes e menos agressivas.

(...) minhas crianças como são $1^{\underline{a}}$ série eu costumo dizer que eles são muito apegados, então você começa a conhecer a criança pelo jeito que ela chega (...) (E2)

A literatura aponta ainda a estratégia agressiva como desadaptativa, afirmando que crianças que utilizam este tipo de atitude alcançam somente uma resolução em curto prazo do problema e são freqüentemente rejeitadas por companheiros. No entanto, considerando a realidade social em que estas crianças e adolescentes vivem, pode-se supor que exista uma dificuldade para resolver os problemas de uma forma mais adequada ou que, muitas vezes, a agressividade é a única forma possível de enfrentamento. Pode-se considerar, também, que 0 uso da agressividade é um modelo observado por eles para resolução de conflitos ${ }^{\text {(11-13) }}$.

Ainda neste âmbito, foi ressaltado que as crianças e adolescentes que não sofreram violência doméstica têm maior controle sobre a própria violência, partindo do pressuposto de que todas as pessoas possuem certo grau de violência a depender de fatores como a paciência e a tolerância. Também foi apontada a 
problemática resultante da dificuldade destas crianças e adolescentes em conhecer seus limites e o respeito ao próximo, como apontam as falas:

(...). só que as crianças que não sofreram agressividade ou qualquer outro tipo de violência têm mais controle da própria violência humana, né, porque nós todos somos meio violentos, dependendo da paciência, né. Elas acham que é normal, natural, uma explosão de vez em quando, bater em alguém. (E1)

(...) ela não se adapta em outro lugar. (...) eles têm um comportamento terrível. Eles têm que entrar porque infelizmente eles não têm limites. Então você tem que mostrar pra eles os limites. (E2)

Outra questão abordada está relacionada à baixa auto-estima das crianças e adolescentes, sendo destacado a desestrutura emocional e familiar como fatores desencadeantes desta, e ressaltado como oriundas deste sentimento, as alterações de comportamento.

O maior problema é a desestrutura emocional que a criança tem... Então essas crianças você tem que estar trabalhando esta parte emocional. O J uma das vezes chegou a falar pra mim que ele tava lá porque a mão dele não queria. Brinquei com ele: J por que você foi parar no CACAV? Ele falou: porque minha mãe não me quis mais e me deu pro juiz (...) ele mesmo falou. (E2)

(...) a questão da auto-estima, né. (...) Eu tento e você percebe nesses alunos que não chegam nem a copiar, e já falam: ah, eu não vou conseguir fazer. Mas aí você tem que trabalhar aquele outro lado, vamos tentar você é capaz. Acho que isso a gente tem que trabalhar muito com eles: você é capaz. (...) Porque você tem que melhorar a auto-estima do aluno (...) (E3)

A auto-estima é compreendida como um juízo pessoal de valor, externado nas atitudes que o indivíduo tem consigo mesmo. É uma experiência subjetiva, à qual as pessoas têm acesso mediante relatos verbais e comportamentos observáveis. A percepção que o indivíduo tem do seu próprio valor e a avaliação que faz de si mesmo em termos de competência constituem pilares fundamentais da auto-estima, sendo desenvolvida desde a infância $^{(12)}$.

Os sujeitos da pesquisa relacionaram, ainda, a questão da baixa auto-estima com a problemática da desestrutura familiar, inclusive ponderando que as mães também possuem uma baixa auto-estima, e que os filhos acabam trazendo muito desta realidade para a escola.

Sabe, porque essas crianças às vezes nem tão no CACAV, mas a mãe fala: ah, esse menino é um burro, ah, ele não vai saber nada, não faz nada (...) elas não têm uma estrutura, as mães têm uma auto-estima baixa. Então é uma desestrutura familiar, tem que trabalhar com a família. (E2)

Porque cada um vivencia e traz da sua realidade alguma coisa que pode interferir no meio social (...) porque ela não é só um serzinho aqui isolado de passado da vida dela, ela carrega tudo junto. (E6)

Pessoas significativas para a criança e para o adolescente tomam lugar de destaque na formação da auto-estima, em especial pais, professores e amigos. Assim, se essas relações forem constituídas por atitudes violentas, parece haver maior probabilidade de serem associadas a um sentimento negativo de si: a baixa auto-estima. O contexto familiar tem sido identificado como a rede de apoio mais próxima durante a infância, e um importante fator protetivo, pois a presença de características na família como, afeto, intimidade e comunicação, pode ajudar as crianças a manterem um senso de estabilidade e rotina frente a mudanças e situações estressantes. Estes sentimentos citados de desvalorização manifestados pela baixa auto-estima, e características pessoais destrutivas (condutas anti-sociais e violentas) podem ser vistos como reflexo da vivência de maus-tratos na infância e identificação com o agressor $^{(11,13)}$.

Embasados em todas estas questões que foram levantadas, os professores percebem que há uma necessidade emergente em se trabalhar as famílias dentro do cenário escolar, apesar de reconhecerem 0 alto grau de dificuldade encontrado para o desenvolvimento de intervenções específicas.

(...) a gente não pode se apoiar na estrutura familiar, a gente não pode deixar que a família 
seja o pivô da não aprendizagem. Ela influencia muito no rendimento escolar do aluno, agora de uma certa forma a escola tem que fazer o melhor dela pra suprir essa falta. (...) Porque é como eu te falei no começo, a família é tudo pra eles, é o que eles têm, o mais sagrado, então a gente tem que se aliar à família pra fazer que ela seja nossa parceira. (E3)

Trazer o pai, a mãe, alguém da família pro espaço escolar acho que é fundamental, né, pra entender a história dessa criança. (E6)

Embutida nas falas dos entrevistados observamos que ocorre uma estigmatização das crianças e adolescentes provenientes do CACAV por parte dos professores e funcionários, das escolas e dos demais alunos. Estes comentários podem ser colocados como barreiras para a reinserção no espaço escolar de crianças e adolescentes institucionalizados.

(...) eu, por exemplo, tive muito problema com a G, ela vai e volta lá pro CACAV porque ela não se adapta em outro lugar (...) Mas é infelizmente uma menina que não tem futuro nenhum. Você pensa o que vai ser da G... é digna de dó. (E2)

(...) as crianças começam a perguntar: tia, mas porque a perua vem trazer e buscar eles? Então logo as outras crianças percebem que aquela criança, né, às vezes vem uma pessoa, e eles falam: ah, é a mãe dele! Não, não é. (...) E aqui na escola ainda teve o caso do $\mathrm{S}$ e da $\mathrm{E}$ que foram pra lá e agora voltaram pra família. Entendeu o caso do $\mathrm{S}$ e da $\mathrm{E}$ é um pouco que ficou assim, muito marcado - as crianças viram eles machucados, a ocorrência foi feita aqui na escola, têm crianças que são vizinhas dela, então viam a situação, tavam sempre comentando dentro da sala. (E2)

Em estudo com adolescentes de classes populares $^{(14)}$, observou-se que aqueles que tiveram vivência institucional apesar de a caracterizarem como o melhor período de suas vidas, relacionando-a com o estabelecimento de novos vínculos, em contrapartida demonstraram sofrer um forte estigma social, pois são vistos pela sociedade como responsáveis e donos de algum tipo de "defeito" ou problema.

\section{Olhar diferenciado - necessidades de apoio}

Dentro deste núcleo houve uma divergência de opiniões sobre a questão que envolve o tratamento diferenciado das crianças e adolescentes vitimizados por parte dos professores e funcionários. Porém, mesmo aqueles que acreditavam que a criança e o adolescente deveriam ser tratados igualmente, destacaram a necessidade de um olhar diferenciado, um tratamento especializado, conforme está evidenciado nas falas a seguir:

(...) eu acho que tem de ser tratada igual dentro da escola, só que ela devia ter um tratamento igual entre aspas... não pode diferenciar, mas ela tem que ter uma ajuda, né, porque senão não dá certo. (E4)

Eu percebo muito nessas crianças que tem um problema qualquer com necessidades especiais. Necessidades especiais englobam tudo: aprendizagem, uma carência muito grande que acaba afetando, uma depressão, então ela vem pra essas classes. Essa rejeição toda. (E7)

Os professores relacionam seu trabalho com a figura materna, referindo que muitas vezes ocupam o papel da mãe idealizada na vida destas crianças e adolescentes.

Os professores daqui tão muito acostumados com esses casos, a gente é muito mãe. Acho que então se você for fazer uma pesquisa com eles, esse lado afetivo eles encontram muito aqui. (...) então assim às vezes eu falo, olha na hora do recreio se você quiser ficar comigo um pouquinho mais, a gente conversa mais, então a gente se mostra assim presente, o que eles quiserem contar eles contam. (E3)

Cada esfera da vida, tais como família, amigos, profissão, vizinhos, escola, instituição de abrigo, entre outros, assumem o papel de identidade social capaz de fornecer apoio nas relações que o indivíduo estabelece com os outros. Quando uma criança tem sua primeira rede de apoio, que é a família, desconfigurada, o mundo social expande-se ainda mais. A relação estabelecida com os monitores e professores, entre outras pessoas que apresentam algum grau de significado para estas crianças e adolescentes abrigados, desempenham papel central na vida das mesmas, à medida que serão estes adultos que assumirão o papel de orientá-los e protegê-los, 
constituindo, neste momento, os seus modelos identificatórios ${ }^{(15)}$.

Os relatos dos professores e funcionários revelam a necessidade de se trabalhar a desestrutura emocional destas crianças e adolescentes, tomando para si uma parte que não lhes é de âmbito profissional e que não têm preparo psicológico ou educativo nenhum para realizá-la.

Outro dia uma moça do CACAV que veio, porque o JV falava pra mim que ia ser desabrigado, logo depois que $\mathrm{O} R$ foi. $\mathrm{Eu}$ perguntei pra ela, mas ela falou não, a mãe do JV tá presa, sabe... Às vezes cria uma expectativa. Que são coisas que você deixa influenciar no seu trabalho. Então tem que ir contornando (...) tem que trabalhar este outro lado. (E2)

Por mais difícil que seja, tem dia que você sai daqui, hoje eu tô assim... Essa escola é uma escola diferenciada, a nossa clientela são alunos que precisam muito desse contato humano, mesmo. Não é só a questão do número, do conteúdo, mas trabalhar também a questão do sentimento, da emoção. (...) Porque você tem que melhorar a auto-estima do aluno, mas para que você faça isso você tem que estar bem também. (E3)

Porque eu acho que a criança é um bem precioso. Inda mais na idade que eles tão de construir a personalidade, como é que você vai lidar com eles no futuro, então a gente não tem esse preparo. (E4)

Sendo assim, percebemos a necessidade de se ter um trabalho com estes professores e funcionários, pois lidam diariamente com situações de violência doméstica que são questões de alta complexidade, comprometedoras e que exigem um preparo psicológico, ético, político e social para uma melhor atuação.

Apesar das atitudes dos professores e funcionários estarem permeadas pela escuta efetiva, paciência e solidariedade, algumas falas demonstraram uma discordância e posturas inadequadas contradizendo esta escuta e paciência.

(...) teve até uma vez que eu perdi a paciência: não você não se dá bem com ninguém na classe menino, pára um pouco pra pensar em tudo que você ta fazendo de errado. (E1)

(...) porque eu acho que eles têm que ter um ponto de apoio, e ao mesmo tempo você tem que ser um ponto de apoio, você não pode deixar essa parte emocional deles te influenciar - você ficar toda derretida pro lado deles, e deixar fazer tudo. Tem que ser um ponto de apoio firme. (E2)

Sabe, tinha que ser dura com ela (...) então você tem que mostrar sua autoridade pra eles. (E2)

O autoritarismo manifestado, por exemplo, no espaço escolar por parte dos professores, em muitas situações pode comprometer uma relação de confiança. A relação professor-aluno acaba sendo permeada pela falta de limites e de respeito, criando uma barreira para uma relação empática, tão necessária para a proteção e cuidado ao aluno no ambiente escolar, além de favorecer uma baixa auto-estima ${ }^{(12)}$.

Diante destes aspectos, ressaltamos a necessidade de se ter nas escolas pessoas habilitadas e potencialmente comprometidas a fornecer uma melhor atenção a crianças e adolescentes, principalmente aquelas vítimas de violência doméstica, seja esta confirmada ou não, além de uma rede de apoio.

$\mathrm{Na}$ opinião dos professores e funcionários são imprescindíveis para o cenário escolar profissionais como psicólogos e assistentes sociais, para que se possa trabalhar a baixa auto-estima, as alterações emocionais e comportamentais e a questão social, tão precária nesta população, se responsabilizando também pela assistência às famílias.

Dentro das modalidades de atenção a crianças e adolescentes vitimizados e institucionalizados, o trabalho em equipe multidisciplinar configura-se como o modelo adequado e com maior eficácia. Nesse aspecto, torna-se importante o conhecimento dos recursos da comunidade onde esta família está inserida, construindo assim uma rede de recursos $^{(15)}$.

Os funcionários citaram programas e/ou projetos que foram iniciados com psicopedagogas, e que apresentaram resultados extremamente positivos e com melhoras 
significativas de crianças e adolescentes vitimizados. Porém estes programas não tiveram incentivos para continuarem e foram extintos.

Em nosso estudo, ficou evidenciado que a falta de conhecimento ou preparo para lidar com estas questões é um fator preponderante para o sigilo no caso de uma suspeita de violência doméstica, conforme mostrado a seguir:

(...) muda muito as leis, a gente não tem aquele preparo, estudo, eu acho que muita coisa barra porque a gente não conhece. I gual esse ECA, eu comecei a ler quando fazia o magistério, depois acabei e parei. Então tem muita coisa que você quer agir e é barrado, porque você não sabe como agir. Tinha que ter um esclarecimento melhor. (E4)

Segundo um estudo realizado acerca do sentido do silêncio dos professores diante da violência doméstica sofrida por seus alunos ${ }^{(16)}$, foi concluído que existe uma relação de sentidos que é mais forte, as representações que circulam há tempos ainda têm mais força do que o discurso jurídico atual, incapaz de transformar as práticas. Ainda que o discurso jurídico defina o procedimento no caso da violência doméstica ser identificada pelo professor, a fronteira demarcada entre o público e o privado, entre a escola e a família, acaba por silenciar o professor. O silêncio ocorre porque o que se demanda da escola reconhecer e denunciar - é um papel que ela não consegue cumprir; a dúvida que se coloca devido à tensão constitutiva de duas posições em conflito que geram ordens discursivas distintas, leva ao silêncio. Confirmamos esta questão pela fala abaixo:

Tem que se preocupar com a segurança da criança e de nós mesmos. A criança tem medo, a segurança da direção, chega na hora a criança desmente, porque isso dá cadeia, né. (E7)

Em nosso país, prevalece uma vasta dificuldade em conhecer a dimensão exata dos casos de violência doméstica, pois tal situação permanece sendo um assunto privado, guardado no território sagrado da família. Além disso, a vergonha e muitas vezes o medo são fatores que dificultam estatísticas confiáveis e estratégias e intervenções adequadas.
Denunciar esse tipo de violência é uma tarefa essencial, uma vez que o silêncio perdoa o agressor e reforça seu poder sobre a vítima ${ }^{(17)}$.

Isto posto, percebemos ainda que, há uma iniciativa por busca de mudanças que pode ser - caminho para modificarmos o curso da violência doméstica no cenário escolar. A sociedade ainda desvaloriza muito a categoria do educador, fazendo com que o aluno também o desvalorize. O respeito ainda é uma palavra que flutua dentro do dicionário; para fixá-la é necessária uma colaboração de ambas as partes $^{(12)}$. Estas questões são evidenciadas nas falas que se seguem:

É questão profissional - hoje nós educadores queremos isso, não só a valorização salarial, mas sim do seu lado profissional, acreditar no que cada educador pode oferecer, valorizar, porque infelizmente acho que a gente tá muito desacreditado, sabe. E a gente profissionalmente ainda tá ficando muito aquém no sentido de valorização. (E3)

Por isso que agora nós tamos entrando pelo sindicato pra ter um programa que chama PróFuncionário, funcionários qualificados pelo Estado pra lidar melhor com as crianças, saber o que está acontecendo pra poder ajudar. (E4)

Quando os sujeitos do estudo foram questionados sobre as barreiras que poderiam existir nas escolas para a reinserção de crianças e adolescentes vitimizados e institucionalizados, foram quase que unânimes em ressaltar que a escola, pelo menos aquela em que eles trabalhavam, não criava nenhuma dificuldade para que estes alunos freqüentassem a instituição.

(...) se existe é não perceptível, tá. (E1)

Olha, eu não vejo barreira nenhuma aqui na escola, o problema (...) na escola, nós sempre acolhemos bem, nunca tivemos problemas, entendeu...(E2)

\section{CONSI DERAÇÕES FI NAIS}

Retomando nosso caminhar neste estudo, percebemos que a problemática da auto-estima foi destacada pelos professores e funcionários como fator explicativo para o comportamento das crianças e adolescentes no espaço escolar. O contexto familiar foi pautado como "fator desencadeante" para esta baixa auto-estima. 
Evidenciamos que estas crianças e adolescentes sofrem uma estigmatização muito forte pelos colegas e até mesmo pelos professores e funcionários, sendo que este fato pode ser apresentado também como barreira para a reinserção escolar e contribuir para o desenvolvimento de sentimentos de rejeição por parte destas crianças e adolescentes, sem, no entanto ser assumido pelos atores sociais deste estudo.

Quanto à maneira de se trabalhar com estas crianças e adolescentes, ficou evidenciado que os professores e funcionários têm uma concepção de que devem ter um tratamento diferenciado. Foi destacada a falta de preparo em vários níveis (psicológico, emocional, educacional) por parte dos professores e funcionários em trabalhar as questões advindas da problemática da violência doméstica, inclusive dando-se ênfase à necessidade de se ter profissionais especializados, psicólogos e assistentes sociais, para oferecer um suporte tanto para as criança e adolescentes, quanto para suas famílias, professores e funcionários.

Destacamos a necessidade de se trabalhar a percepção acerca da reintegração no espaço escolar de crianças e adolescentes vitimizados e institucionalizados sob a ótica de outros sujeitos, pois percebemos que os professores e funcionários tendem a preservar as escolas em que estão inseridos ao relatarem que estas instituições não construíam barreiras para que essas crianças e adolescentes as freqüentassem.

Consideramos ainda que, os temas centrais articulam-se com a necessidade de se voltar um enfoque especial às crianças $e$ adolescentes institucionalizados e vitimizados e aos profissionais que as assistem. Devemos olhar a violência doméstica como um problema multifacetado, que requer a estreita cooperação e integração multiprofissional e intersetorial. Entre os profissionais, é imprescindível trabalhar os professores e funcionários das escolas freqüentadas por estes atores, já que esta instituição ocupa um papel primordial no desenvolvimento físico, cognitivo, emocional e social destes alunos. Requer também, do ponto de vista judicial, o conhecimento dos aspectos criminais e de proteção à criança e ao adolescente. Envolve as crianças e adolescentes como seres humanos estruturalmente dependentes, que são pessoas com seus próprios direitos mas que não podem exercer esses direitos por elas mesmas, precisando de proteção e do cuidado dos pais. Quando estes pais se mostram omissos, e a criança ou o adolescente percebe a fragilidade da família em que está inserido, ele busca na escola e nas pessoas que fazem parte dela um apoio e estratégias de enfrentamento desta situação.

A violência doméstica contra crianças e adolescentes e suas nuances impõem-se como exercício para compreender a dinâmica atual da família e da sociedade. No contexto da enfermagem, a temática é considerada emergente, necessitando de maiores estudos que possam subsidiar o preparo dos profissionais para um melhor cuidado e atenção à criança e ao adolescente vitimizados. Estudos confirmam o preocupante agravamento da mortalidade por causas violentas entre crianças e adolescentes brasileiros, porém sabemos que estes casos representam apenas o ápice da pirâmide, em que a base - os casos não fatais estão em sua maioria encobertos. Conhecer um pouco mais sobre esse assunto nos permitirá subsidiar melhor as ações voltadas para uma assistência integral à criança e ao adolescente, seja na promoção, prevenção ou recuperação da saúde.

Novos estudos que objetivem a avaliação da reinserção social de crianças e adolescentes institucionalizados e vítimas de violência doméstica sob diferentes olhares e que busquem aprimorar um referencial teóricoanalítico, capaz de permitir a compreensão desse fenômeno na especificidade que ele tem hoje, podem ser o caminho para novos conhecimentos e direcionamentos que possibilitem a promoção dos direitos, da proteção e da cidadania desta população.

\section{REFERENCI AS}

1. Data SUS [Internet]. Brasília: Ministério da Saúde (BR) [cited 2008 mar 28]. Informações de saúde. Available from: http://tabnet.datasus.gov. br/cgi/tabcgi.exe?sim Lcnv/obtuf.def. 
2. Minayo MCS, Souza ER, editores. Violência sob o olhar da saúde: a infrapolítica da contemporaneidade brasileira. $8^{a}$ edição. Rio de Janeiro: Fiocruz; 2003.

3. Pereira SM, Santana JSS, Ferriani MGC. Violência rima com adolescência? In: Ramos FRS, editor. Adolescer: compreender, atuar, acolher. Projeto Acolher / Associação Brasileira de Enfermagem. Brasília: ABEn; 2001. p. 95103.

4. Roque EMST. Estudo das famílias de crianças e adolescentes vítimas de violência que sofreram intervenção da justiça, no município de Jardinópolis-SP [tese]. [Ribeirão Preto]: Escola de Enfermagem de Ribeirão Preto/USP; 2006. 278 p.

5. Neves AS, Romanelli G. A violência doméstica e os desafios da compreensão interdisciplinar. Estudos de Psicologia (Campinas) [Internet]. 2006 [cited 2008 mar 27];23(3):299-306. Available from: http://www. scielo.br/pdf/estpsi/v23n3/v23n3a09.pdf. 6. Algeri S, Souza LM. Violence against children and adolescents: a challenge in the daily work of the nursing team. Rev. Latino-Am. Enfermagem [Internet]. 2006 [cited 2008 mar 28]; 14(4):625-631. Available from: http://www. scielo.br/pdf/rlae/v14n4/v14n4a23.pdf.

7. Pinheiro PS. Violência contra crianças: informe mundial. Ciênc. saúde coletiva. 2006; 11(supl): 1343-50.

8. Brasil. Ministério da Saúde. Estatuto da Criança e do Adolescente. 3ạ edição. Brasília: Ministério da Saúde; 2007.

9. Minayo MCS, editor. Pesquisa Social: teoria, método e criatividade. Petrópolis: Vozes; 2007.

10. Bardin L. Análise de conteúdo. Lisboa: Edições 70; 2002.

11. Dell'Aglio DD, Hutz CS. Estratégias de Coping de Crianças e Adolescentes em Eventos Estressantes com Pares e com Adultos. Psicologia USP [Internet]. 2002 [cited 2007 aug 01];13(2):203-225. Available from: http://www.scielo.br/pdf/epsic/v7n1/10949.pdf. 12. Marriel LC, Assis SG, Avanci JQ, Oliveira RVC. Violência escolar e auto-estima de adolescentes. Cadernos de Pesquisa [Internet]. 2006 [cited 2007 aug 01];36(127):35-50. Available from:
13. Assis SG, Avanci JQ, Santos NC, Malaquias JV, Oliveira RVC. Violência e representação social na adolescência no Brasil. Rev Panam Salud Publica. 2004; 16(1): 43-51.

14. Parreira SMCP, Justo JS. A criança abrigada: considerações acerca do sentido da filiação. Psicologia em estudo [Internet]. 2005 [cited 2008 mar 27]; 10(2):175-180. Available from: http://www. scielo.br/pdf/pe/v10n2/v10n2a03.pdf.

15. Garcia MRC. Teorias e técnicas do atendimento social em casos de violência intrafamiliar na infância e na adolescência. In: Ferrari DCA, Vecina TCC, editores. O fim do silêncio na violência intrafamiliar. São Paulo (SP): Agora; 2002. p. 143-152.

16. Panuncio-Pinto MP. O sentido do silêncio dos professores diante da violência doméstica sofrida por seus alunos: uma análise do discurso [tese]. [São Paulo]: Instituto de Psicologia da Universidade de São Paulo; 2006. $178 \mathrm{p}$.

17. Ribeiro MA, Ferriani MGC, Reis JN. Violência sexual contra crianças e adolescentes: características relativas à vitimização nas relações familiares. Cadernos de Saúde Pública. 2004; 20(2):456-464.

Artigo recebido em 20.08.07

Aprovado para publicação em 30.06.08 